\title{
SIMILARIDADES E DIFERENÇAS GRÁFICAS NAS CENAS DE CAÇA NA ÁREA ARQUEOLÓGICA SERRA DA CAPIVARA
}

\section{SIMILARITIES AND GRAPHIC DIFFERENCES IN THE HUNTING SCENES AT SERRA DA CAPIVARA ARCHAEOLOGICAL AREA}

\author{
Daniela Cisneiros ${ }^{1}$ \\ danielacisneiros@yahoo.com.br \\ Leonardo de Morais Borges ${ }^{2}$ \\ leonardo.morais.borges@gmail.com
}

\section{RESUMO}

Este artigo fornece um estudo das cenas de caça nos sítios com registros rupestres do Parque Nacional Serra da Capivara. Em decorrência da persistência dos registros rupestres no tempo, estes apresentam um caráter dinâmico. O corpus graficus de um sítio está sujeito a um fluxo contínuo de alterações dadas muitas vezes por adição de novos grafismos em sobreposição ou em interação com outros. Com o objetivo de identificar similaridades e diferenças gráficas nas cenas de caça, a presente pesquisa partiu da análise temática e cenográfica dos elementos (zoomorfos e antropomorfos) contidos nessas cenas. Os resultados destacam diferenças na execução gráfica de elementos contidos em uma mesma cena.

Palavras chaves: Registro Rupestres, Parque Nacional Serra da Capivara; Cenas de caça.

\section{ABSTRACT}

\footnotetext{
${ }^{1}$ Departamento de Arqueologia da UFPE.

${ }^{2}$ Discente do Programa de Pós-graduação em Arqueologia da UFPE.
}

Indexadores: Latindex, ISIS, Google Academic 
This paper provides a study of the scenes of hunting in the sites with rock art of Serra da Capivara National Park. Due to the persistence of the rock art in time, these present a dynamic character. The corpus graficus of a site is subject to a continuous flow of changes often given by the addition of new overlapping graphics or in interaction with others. With the objective of identifying similarities and graphic differences in hunting scenes, the present research started from the thematic and scenographic analysis of the elements (zoomorphic and antropomorphic) contained in the scenes. The results highlight differences in the graphical execution of elements contained in the same scene.

Key words: Rock Art, Serra da Capivara National Park; Hunting scenes

\section{CONTEXTO DA PESQUISA}

Os registros rupestres, vestígios arqueológicos pintados ou gravados em suportes rochosos, estão entre as primeiras manifestações gráficas produzidas pelo Homo sapiens. Essas marcas ou evidências que se materializaram nos suportes rochosos através dos séculos em processos técnicos e físico-químicos, hoje constituem-se em fontes arqueológicas para a compreensão dessas sociedades.

Ao final da polêmica sobre a autenticidade e a antiguidade dos registros rupestres, se intensificaram as pesquisas e explicações sobre esses vestígios na Arqueologia. Atualmente, muitos pesquisadores trabalham com diferentes vertentes investigativas na tentativa de compreender melhor as técnicas, os códigos e as motivações que levaram grupos pré-históricos em distintas épocas e lugares, a pintarem e gravarem desenhos abstratos e/ou naturalistas nos suportes rochosos.

Independente das interpretações possíveis sobre a natureza dos grafismos, esses funcionam como fontes de dados, portadores de informações insubstituíveis fornecidas 
pelos próprios grupos autores. São vestígios arqueológicos deixados intencionalmente para se perpetuem no tempo.

A produção das imagens rupestres leva consigo um componente comunicativo, expressa algo, representa uma mensagem com significados dentro da sociedade para qual foi criada, à parte, evidencia também um processo cognitivo complexo composto por normatizações e regras (Sanchidrián, 2001).

Como componentes de um sistema de comunicação, a execução gráfica dos registros rupestres tem códigos e regras que podem ser identificados a partir do estudo do significante gráfico ${ }^{3}$. Essas regras podem ser observadas na padronização de temáticas, formas de apresentação das figuras, espessura do traço, cor, simetria gráfica, preenchimento, entre outros. A distinção nesses códigos pode expressar distintos grupos ou épocas.

O corpus graficus de um suporte rochoso pode ser um complexo produto de uma acumulação diacrônica, resultado da adição gradual de motivos gráficos a um mesmo painel em acontecimentos sucessivos. Esta acumulação pode ser demonstrada pela variedade morfológica, métrica, temática e de composição expressas no suporte rochoso de um sítio.

As diacronias gráficas podem ser observadas, a partir de diferentes estilos e técnicas gráficas existentes em um mesmo suporte; de sobreposições e da incorporação de novas

\footnotetext{
${ }^{3}$ Significante gráfico corresponde dentro da Semiótica a forma material, a imagem, que toma o signo (Cisneiros, 2008).
} 
figuras às composições já existentes. Em alguns casos as sobreposições interferem no grafismo anterior, restringindo sua visualização a partir da inserção de novos grafismos; em outros casos, essa inserção demonstra um respeito pelas figuras já existentes no espaço físico do suporte, são inseridas entre os espaços vazios sem tocar em outros grafismos. Os novos grafismos complementam figuras já existentes, mantendo ou diferenciando o sentido das cenas, e apoderando-se de elementos gráficos já existentes. $\mathrm{O}$ que se observa atualmente nos painéis rupestres, pode ser resultado desses reagenciamentos gráficos, orientados a partir de grafismos já existentes. Essa pesquisa tem como objetivo analisar as similaridades e as diferenças gráficas dos componentes expressos nas cenas de caça dos sítios com pinturas rupestres na Área Arqueológica Serra da Capivara.

\section{ESTUDOS SOBRE OS GRAFISMOS RUPESTRES NA SERRA DA CAPIVARA}

A Área Arqueológica Serra da Capivara apresenta a maior concentração de pinturas rupestres das Américas e comporta em seu acervo gráfico distintas manifestações que diferem-se em realizações técnicas, escolhas temática e cenográficas.

Dentro do panorama inicial dos estudos sobre registros rupestres no Brasil, Guidon (1975) propôs um ordenamento preliminar das características gerais dos grafismos rupestres para a região. A proposta, pautava-se na constatação de que os grupos autores imprimiam sobre a rocha particularidades gráficas próprias de sua cultura, partindo dessa premissa, grafismos diferentes poderiam pertencer a horizontes culturais também diferentes. 
O primeiro critério técnico para o tipo de ordenamento proposto foi baseado na taxonomia dos vestígios. Esse critério distinguia dois grandes grupos em relação ao plano tecnológico: grafismos pintados e grafismos gravados (Cisneiros, 2008).

O segundo critério utilizado referia-se ao reconhecimento cognitivo que ofereciam os grafismos. Alguns permitiam conhecer elementos do mundo sensível, enquanto outros eram sinais gráficos sem possibilidade de reconhecimento (Pessis, 1992). Dentro das figuras reconhecíveis foram identificadas duas classes de pinturas: uma, em que as figuras representavam pessoas e animais desenvolvendo ações e outra, em que as figuras representavam pessoas e animais em posição estática, sem o desenvolvimento de ação (Cisneiros, 2008).

Esse método permitiu gerar um número de dados suficientes para poder segregar grupos de grafismos para análise. Assim, de forma preliminar esses grafismos foram segregados em tradições ${ }^{4}$. Para a Área Arqueológica da Serra da Capivara foram definidas e estudadas: uma tradição de gravuras - Itaquatiara e duas tradições de pinturas: tradição Nordeste e tradição Agreste. Essa pesquisa, porém, está centralizada nos componentes gráficos da Tradição Nordeste.

A Tradição Nordeste pode ser identificada pela variedade dos temas representados (antropomorfos, zoomorfos e fitomorfos) e pela riqueza de enfeites e atributos que acompanham as figuras humanas. Essas figuras reconhecidas são, muitas vezes, dispostas

\footnotetext{
${ }^{4} \mathrm{O}$ que se buscou estabelecendo tradições foi a integração de obras gráficas pertencentes a um mesmo grupo cultural, independentemente de unidades cronológicas, procurou-se identificar as características dos registros próprias do meio cultural ao qual os autores pertenciam (Pessis, 1992).
} 
de modo a representar ações, cujos temas são, às vezes, reconhecíveis (Pessis, 1987; 1993).

O maior traço distintivo deste conjunto são as figurações naturalistas e dinâmicas envolvidas em cenas cotidianas (dança, guerra, sexo) que são habilmente representadas, utilizando a técnica de traços leves e seguros. A presença de zoomorfos e antropomorfos se dá de forma bastante equilibrada, e muitas vezes em associação e situações coletivas como caça, coleta, cenas de bando (Martin, 1999).

Partindo do objetivo de encontrar parâmetros mais afinados para contribuir com o reconhecimento da identidade cultural dos autores dos grafismos dessa Tradição, Pessis (1987) estabeleceu critérios para classificar os grafismos da Tradição Nordeste em subtradições $^{5}$, foi considerada para Área Arqueológica Serra da Capivara a subtradição Várzea Grande.

Aplicando critérios que visavam o estudo das dimensões gráficas: temática, técnica e cenografia, foi possível identificar dentro dessa subtradição dois estilos gráficos ${ }^{6}$ e um complexo estilístico (Pessis, 1992). O estilo Serra da Capivara, realizado na fase inicial da Tradição Nordeste e estilo Serra Branca, na fase final da mesma Tradição. Na fase intermediária entre os dois estilos, evidencia-se o Complexo Estilístico Serra Talhada.

\footnotetext{
${ }^{5} \mathrm{O}$ conceito de subtradição está fundamentado na constatação de que existem figuras com diferentes formas, em espaços geográficos diferentes. Esses grafismos apresentariam novos elementos técnicos e temáticos incorporados, a partir de novos ambientes e novas experiências.

${ }^{6}$ Os estilos gráficos compõem uma unidade mais particularizada de análise. A noção de estilo trabalhada por Pessis (1989) para os grafismos da Área Arqueológica Serra da Capivara corresponde a unidades compostas por uma estrutura de apresentação e técnicas gráficas destacadas no interior das categorias de entrada estabelecidas para o estudo dos registros rupestres. Os estilos seriam, portanto, categorias que, associadas a uma cronologia permitiriam precisar identidades gráficas (Cisneiros, 2008).
} 
Cada um dos estilos corresponde a uma unidade cultural identificada segundo estruturas de apresentação e técnica gráfica somadas a um contexto arqueológico.

\section{Cenas de caça}

As pinturas rupestres dessa área assumem em si um forte componente narrativo, materializado por cenas onde interagem zoomorfos e antropomorfos. Apesar da observação de um elevado número de cenas, estas porém não são muito diversificadas em relação ao tema narrativo e também não são dominantes no conjunto gráfico da área, apresentando-se de maneira reduzida quando comparada às demais figuras reconhecíveis da área. As temáticas mais expressas no cenário da Serra da Capivara correspondem a cenas de bando, sexo, violência, caça, lúdicas e cenas de caráter hermético.

O particularismo do conteúdo cênico da amostra estudada reside fundamentalmente no naturalismo dos grafismos, no qual antropomorfos e zoomorfos, se dispersam ao longo da superfície dos abrigos rochosos em atitudes dinâmicas e realistas, demonstrando a partir de elementos gráficos, distintas formas de animais e técnicas de caça.

As cenas de caça particularizadas nessa pesquisa estão compostas por antropomorfos que atiram objetos, perseguem, encurralam ou capturam os zoomorfos.

\section{MÉTODO}

A primeira parte da pesquisa consistiu em um recorte espacial e temático da unidade a ser trabalhada. Adotou-se como unidade física de coleta de amostras os sítios contidos na área correspondente ao Parque Nacional Serra Capivara, localizado no sudeste do Piauí. As cenas de caça que compõe essa pesquisa foram identificadas e selecionadas em prospecções arqueológicas e na consulta ao banco de dados da Fumdham (Fundação 
Museu do Homem Americano), que mantém um amplo acervo de imagens dos grafismos rupestres do Parque Nacional Serra da Capivara.

O corte temático adotado, considerou o princípio da interação entre figuras humanas e animais. Essa interação foi identificada, de modo cognitivo, a partir da gestualidade dos elementos em cena refletindo animais sendo privado de liberdade ou atingidos por armas. Assim, não foram considerados na amostragem cenas em que os animais estão apenas soerguidos (Figura 1).

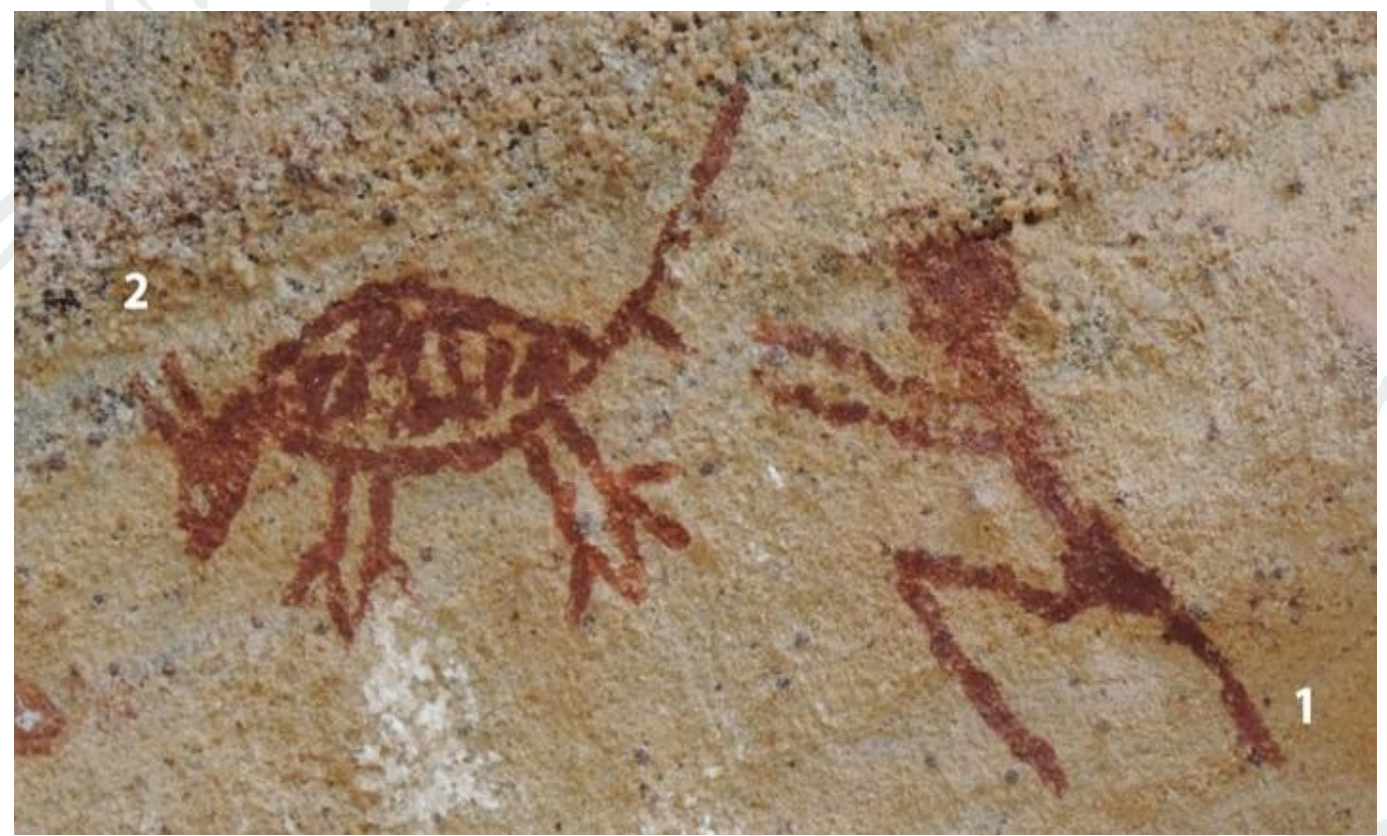

Figura 1: Cena de caça, captura de tatu. Cena 1 do sítio Toca do Boqueirão da Pedra Furada. 1. Antropomorfo com gestualidade de captura; 2. Zoomorfo atitude de fuga.

Seguindo os critérios acima, a amostra selecionada consistiu-se por 42 cenas distribuídas em 24 sítios arqueológicos no Parque Nacional Serra da Capivara (Quadro 1). 


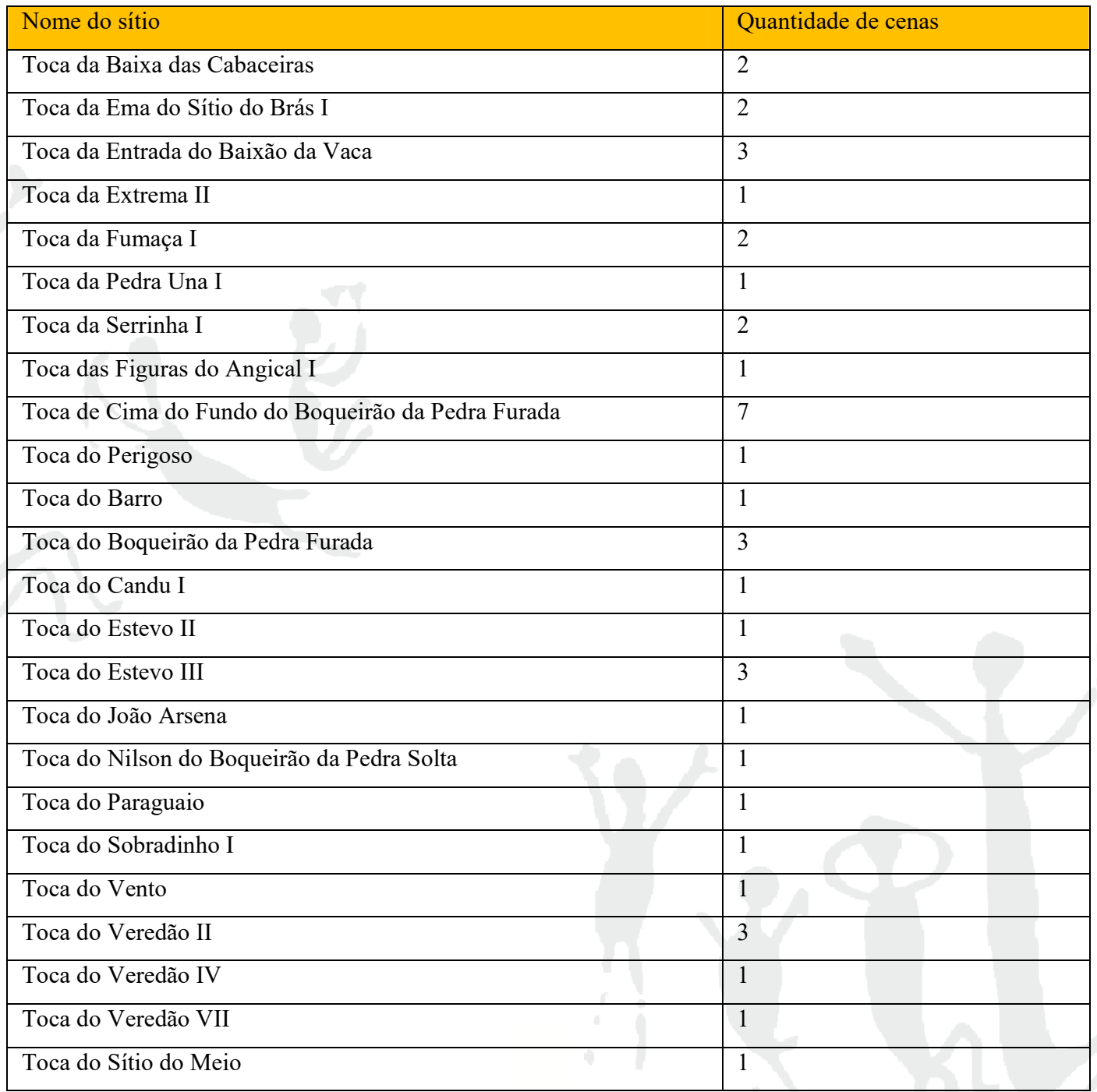

Quadro 1: Relação de sítios e quantidade de cenas de caça contida em cada.

Para esse trabalho foi levado em consideração duas etapas analíticas: a primeira concernente aos aspectos temáticos e cenográficos relativos às espécies caçadas, tipo de caça e número de indivíduos em cena; a segunda corresponde identificação de 
similaridades ou diferenças gráficas entre os elementos envolvidos em cenas, a partir da observação e análise de elementos descritores: cor, nitidez e traço (espessura, tipo contínuo ou descontínuo e precisão).

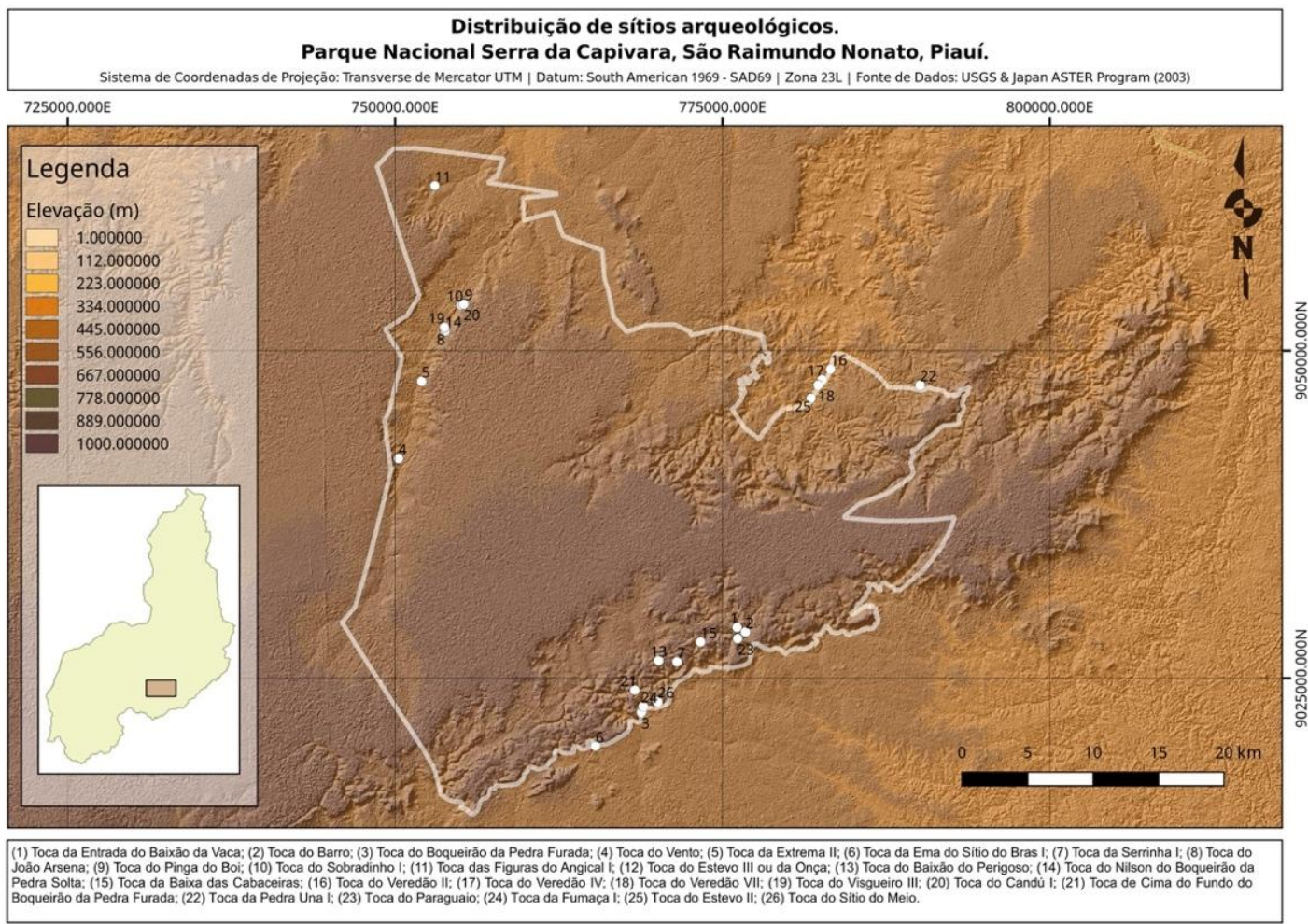

Figura 2: Distribuição dos sítios com cena de caça na área do Parque Nacional Serra da Capivara. 


\section{ANÁLISE E DISCUSSÃO}

A eleição de elementos essenciais na representação do animal a ser representado graficamente, como cabeça, tronco e patas somados à orientação ${ }^{7}$, projeção $^{8}$ e constância ${ }^{9}$, são informações que tornam a figura passível de reconhecimento a partir de uma experiência visual prévia do modelo. Ou seja, além dos elementos essenciais da figura é necessário também que o receptor esteja habituado com aquela imagem no seu cotidiano e em recorrências gráficas, para que possa reconhecê-la.

Nas 42 cenas analisadas, foi possível observar o elevado número de representações de tatus (21) em relação aos demais animais (Gráfico 1) (Figura 3). Entre os outros animais representados estão: veados (12), onças (7), capivara (1) e lagarto (1) (Figuras 4 a 7). As representações de capivaras mais comuns nessa área, são representações de cenas de bando por isso essa representação no sítio Toca do Veredão VII se torna singular. A cena de lagarto caçado, como observado no sítio Toca de Cima do Boqueirão da Pedra Furada, também é única para a área, em geral as representações desse animal dispõem-se de forma isolada.

\footnotetext{
${ }^{7}$ A Orientação espacial - expressa o posicionamento do objeto. Segundo Rudolf Arnheim, (2006), a identidade visual de um objeto depende, de como este já foi mostrado, não tanto de sua configuração como tal, mas do esqueleto estrutural criado pela imagem.

${ }^{8} \mathrm{Na}$ escolha da projeção com o objetivo de criar uma representação sobre uma superfície plana é preciso realizar a tradução da melhor forma, ou seja, representar algumas das características estruturais essenciais do conceito visual por recursos bidimensionais. Assim a vista de topo da figura de um lagarto coloca em evidências aspectos mais notáveis da sua estrutura, que sua vista lateral. Alguns objetos ao serem representados por determinado ângulo, porém podem falsear ou deixar dúvidas a respeito de sua identidade (cisneiros, 2008)

9 Constância - dispõe das proporções de forma e tamanho que são essenciais para o reconhecimento do objeto. As proporções anatômicas das figuras remetem a imagem original.
} 

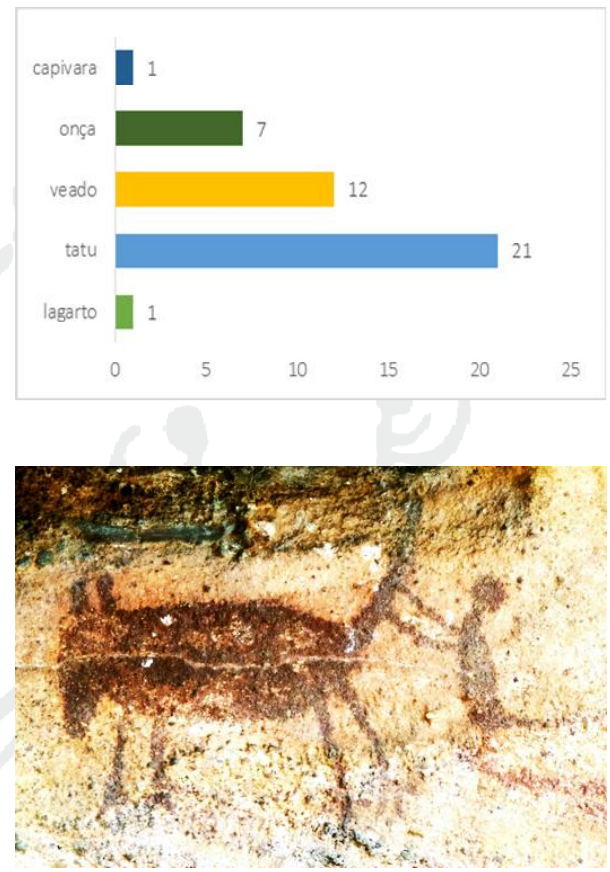

Figura 3: Representação de tatu. Sítio Toca da Fumaça I.

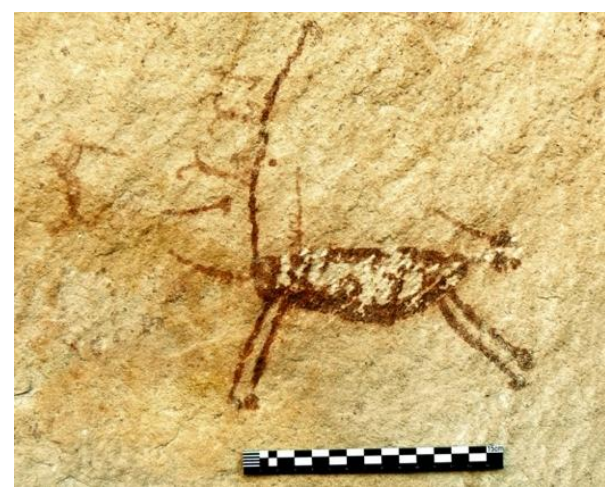

Figura 5: Representação de onça. Sítio Toca do João Arsena.
Gráfico 1: Distribuição das espécies de animais representados nas cenas de caça na Serra da Capivara.

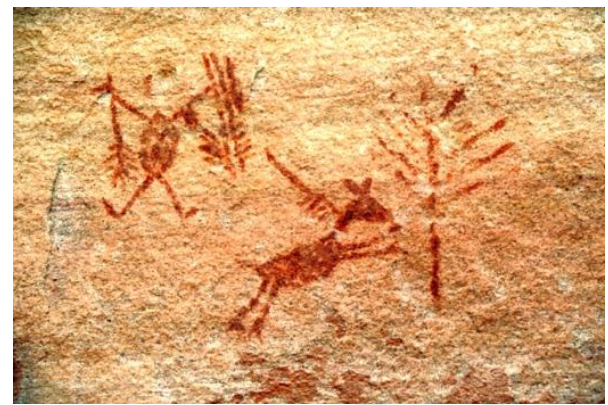

Figura 4: Representação de veado. Sítio Toca do Nilson do Boqueirão da Pedra Solta.

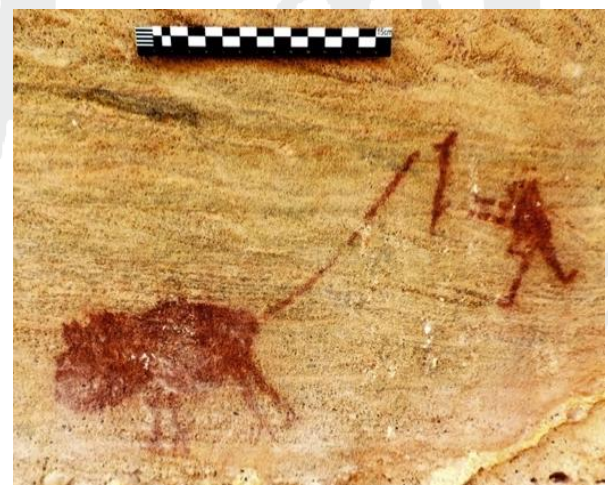

Figura 6: Representação de capivara. Sítio Toca do Veredão VII. 


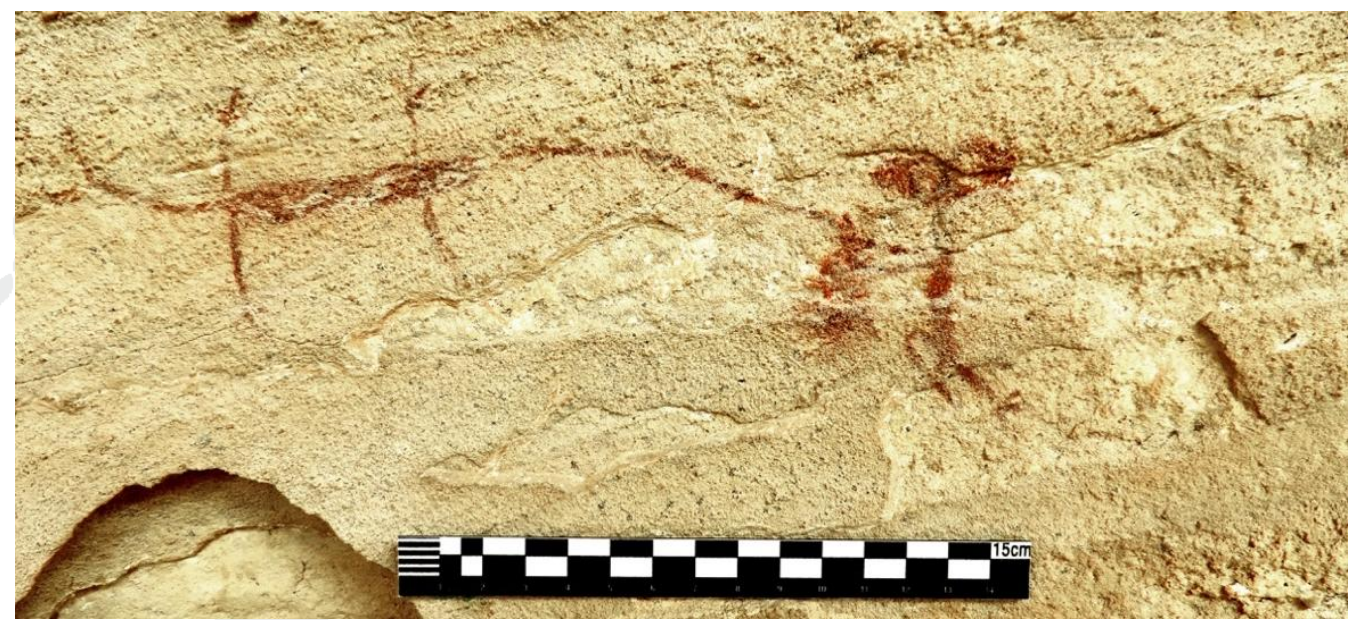

Figura 6: Traços essenciais da imagem remontam cognitivamente a ideia de um lagarto. Sítio Toca de Cima do Fundo do Boqueirão da Pedra Furada.

$\mathrm{Na}$ amostra analisada observou-se que as espécies representadas são pouco variadas, considerando a diversidade faunística característica da região para finais do Pleistoceno e início do Holoceno, que compreendia além dos animais da megafauna, animais da fauna atual (Guerin \& Faure, 2008, 2014; Guerin et al, 1996; Felice et al, 2014; Barbosa, 2017; Valle, 2018). Os animais representados, porém, condizem com os restos faunísticos evidenciados nas escavações de sítios arqueológicos da região tanto em contextos alimentares quanto no seu aproveitamento como matéria-prima para fabricação de adornos (Barbosa, 2017).

As representações tipológicas e repertórios temáticos de animais, foram aqui estudados utilizando o conceito de Panofsky (1986) dos elementos pré-iconográficos, ou seja, a tipologia gráfica. A imagem recebe o significado gráfico relativo aos elementos 
cognitivos de reconhecimento gráfico, assim, para esse trabalho fica restrito ao tema caça em primeira instância.

A segunda variável analisada nos contextos cenográficos foi a técnica de caça. Essa variável buscou compreender como os animais são caçados nas representações evidenciadas no Parque Nacional Serra da Capivara. Nessas cenas foi possível distinguir entre duas técnicas de caça: o apresamento manual e técnicas de caça com a utilização de armamentos (Gráfico 2).

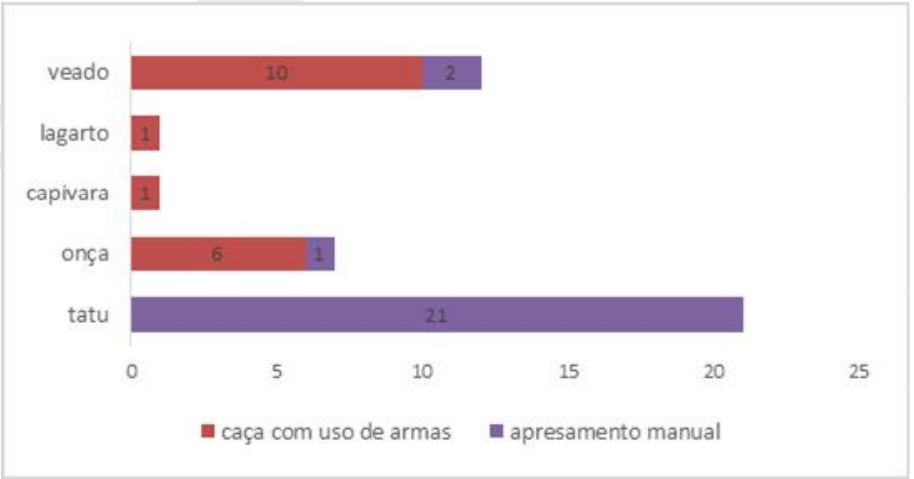

Gráfico 2: Distribuição das cenas de caça com uso de armas e apresamento manual em relação aos animais caçados.

A partir da análise dos componentes do gráfico acima pode-se perceber que a totalidade dos tatus representados, foi apresentada apenas com capturas manuais, com exceção de uma cena no sítio Toca da Entrada do Baixão da Vaca, em que além do apresamento manual, representou-se também um antropomorfo com armas, a essa cena, porém, se fará menção mais adiante. $\mathrm{O}$ apresamento manual refere-se a captura do animal com as mãos, sem a utilização de recursos adicionais. Esse tipo de caça para tatus é uma condição comum na etnografia e na história de grupos caçadores. Outros animais, porém, representados na amostra estudada, sob a forma captura manual como onça (1) e veado 
(2), são mais comuns serem retratados em caças com o uso de armas ou armadilhas, em decorrência de seu tamanho e agilidade.

Os demais animais veados (9), lagarto (1) capivara (1) e onças (6), aparecem sendo capturados com representação de armas. No Sítio Toca do Estevo III (cenas 1 e 2) está representado de forma recorrente um elemento gráfico, no qual nota-se a utilização de uma espécie de rede, ou um elemento de constrangimento do espaço para o animal (Figura 8).
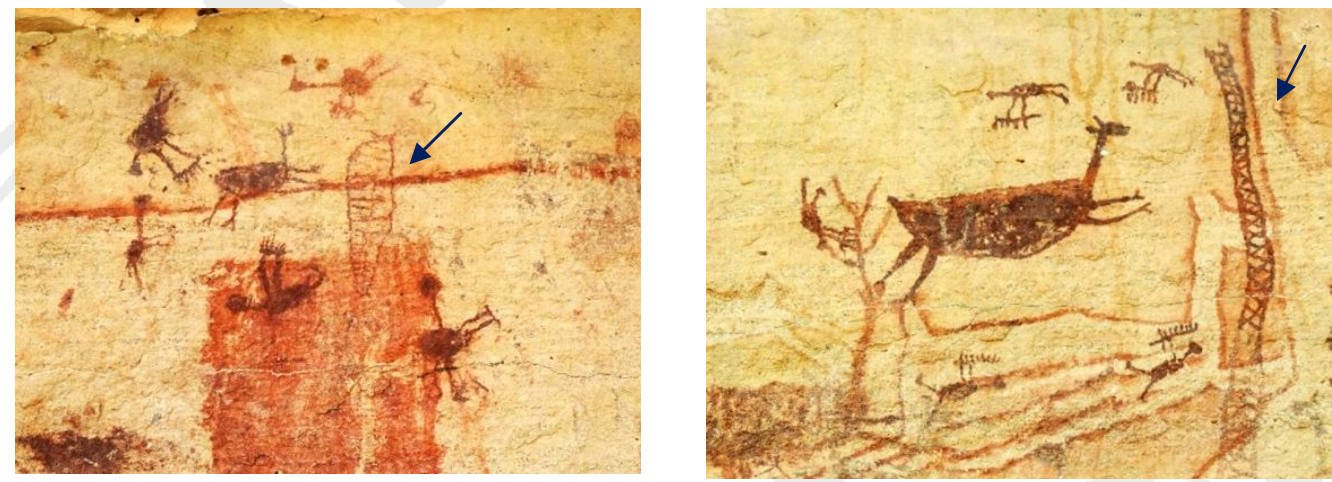

Figura 8: Cenas de caça semelhantes, com estrutura gráfica recorrente (seta azul). Cenas 1 e 2 do Sítio Toca do Estevo III.

A terceira variável cenográfica analisada referiu-se à quantidade de antropomorfos e zoomorfos que participam das cenas (Quadro 2). Na amostra analisada verificou-se que a dominância das representações se direciona para a caça individual, onde um antropomorfo sozinho armado ou não, enfrenta um zoomorfo em sua captura. Esse tipo de caça foi observada predominantemente para os tatus (20); lagarto (1); capivara (1) e veado (8) (Gráfico 3). 


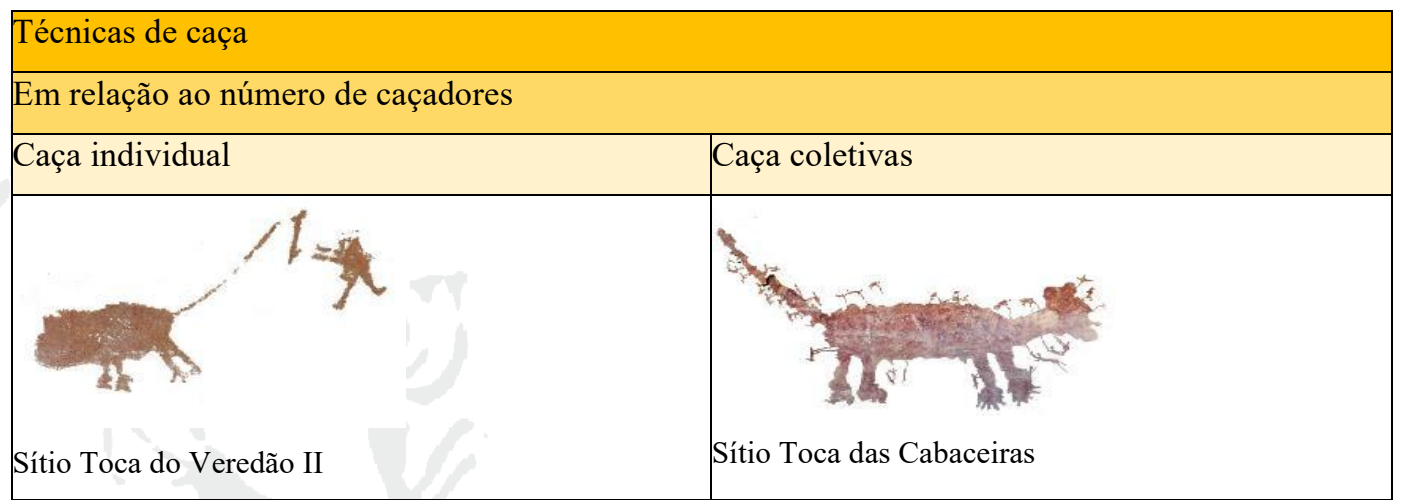

Quadro 2: Demonstrativo de cenas individuais e coletivas de caça.

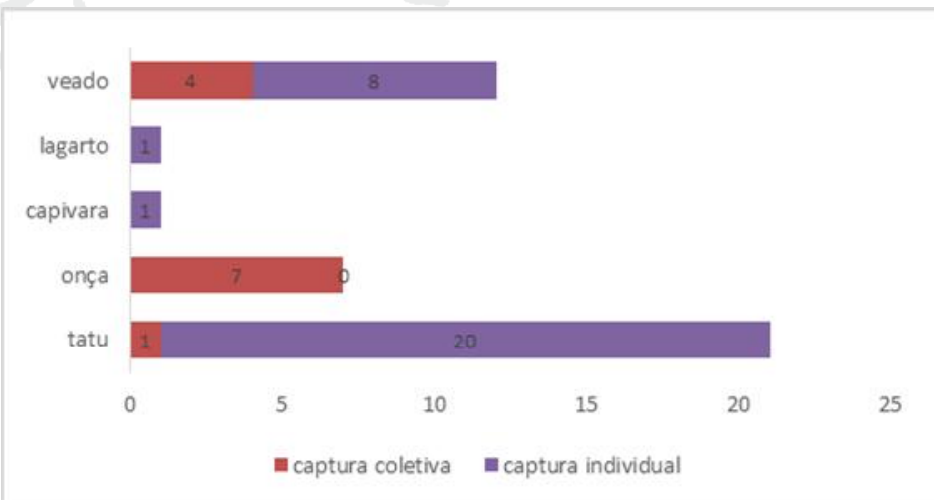

Dentro da amostra analisada o que se faz mais discrepante em termos de caça é a caça individual de veados, que na maioria da amostra é vista em caças coletivas, outra cena de mesma singularidade é a caça coletiva de tatu, essas cenas serão tratadas mais adiante. As caças coletivas, observadas em especial nas caças de onça e de veados, demonstram a existência de uma cooperação entre indivíduos na busca pela presa, para as caças individuais a dominância é para animais de pequeno porte como capivara, tatu e lagarto. 
Em relação ao número de animais caçados, a análise dos dados permitiu observar a quase totalidade das cenas serem compostas por apenas um animal caçado. A exceção está nos sítios: Toca do Veredão IV e Toca do Sítio da Ema do Brás onde participam da cena dois animais. Embora, pode-se constatar em uma avaliação do cenário, que no sítio Toca do Sítio da Ema do Brás as duas figuras são caçadas de forma independente por dois antropomorfos (Figura 9); e no sítio Toca do Veredão IV, apenas um animal é atingido, nesse sítio observa-se também que os animais estão estáticos e não em movimento como recorrente nas cenas de caça (Figura 10). Para as cenas de caça no contexto da Serra da Capivara a caça de bandos de animais não é representação recorrente.

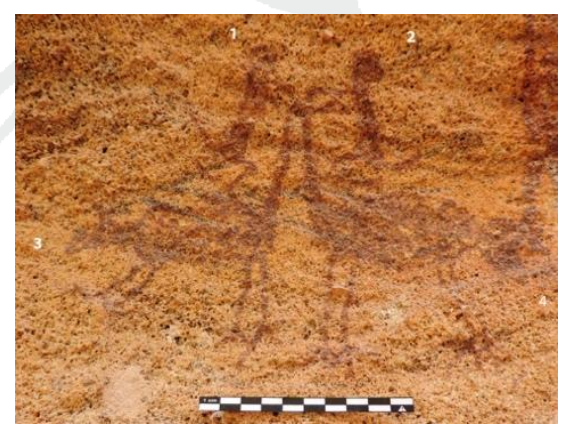

Figura 9: Dois zoomorfos e dois antropomorfos em cena de apresamento manual. Toca do Sítio da Ema do Brás.

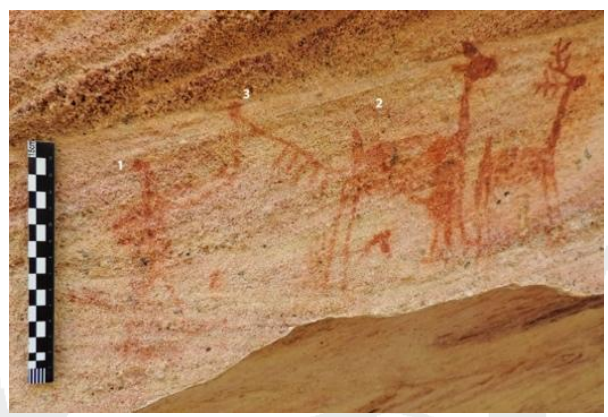

Figura 10: Dois zoomorfos em composição de forma estática e um antropomorfo empunhando uma espécie de arma. Toca do Veredão IV

O segundo nível analítico reporta às características formais, essas características foram cruciais para estabelecer grupos tipológicos significativos, utilizados na segregação dos estilos gráficos para área (Pessis, 1989; 1992). Para essa pesquisa utilizou-se as diferenças e similaridades gráficas, para avaliar a correspondência entre zoomorfos e antropomorfos que compunham as cenas de caça. 
Mediante essa observação foram diferenciados dois grupos: àqueles que teriam similaridades gráficas em relação a cor, a nitidez e ao tipo de traço (espessura, continuidade e precisão), e àqueles que apresentavam diferenças gráficas entre as mesmas variáveis.

A cor, enquanto variável de análise das cenas, tem como objetivo identificar os matizes acusando semelhanças e diferenças em unidades gráficas da mesma cena. A descontinuidade na tonalidade de grafismos em uma mesma cena pode indicar uso de diferentes tintas ou de novas pinturas por cima das já existentes (Quadro 3).

\begin{tabular}{|l|l|}
\hline Cores \\
\hline Elementos de cena em matizes semelhantes & Elementos de cena em matizes diferentes \\
\hline Sítio Toca do Candu & Sítio Toca do Veredão II \\
\hline
\end{tabular}

Quadro 3: Demonstrativo de cenas com elementos representados em matizes diferentes.

$\mathrm{Na}$ análise de cores das figuras, o vermelho mostrou-se dominante. A diferença de tonalidades do vermelho pode ser observada em 2 cenas: Toca do Una I (Figura 13) e Toca do Veredão II (Quadro 3).

A variável cor foi analisada juntamente com nitidez das figuras, sobre o suporte. A nitidez foi observada nos traços das figuras e indica a consistência visual dos limites dos traços e está associada à técnica utilizada, densidade do pigmento, composição da tinta e a ação do tempo em sua conservação. Sabe-se que os fatores de degradação podem agir 
de forma diferente em vários setores de um painel rupestres, e que essa ação depende de um conjunto de variáveis. Com a análise macroscópica da nitidez do pigmento foi observado se a cena teria uma uniformidade, se as pátinas ou eflorescências salinas atingiam a cena como um todo. Essas diferenças podem vira a representar composições de tinta distintas e/ou momentos pictóricos distintos.

Das 42 cenas em estudo, foi verificado que 39 cenas possuem nitidez compatíveis que sugerem correspondência na composição das figuras, enquanto 3 cenas tem ao menos um componente não compatível, estando compreendidas nos sítios Toca da Serrinha I (Figura 11), Toca do Estevão III (Figura 12) e Toca do Veredão II (Quadro 3). Nessas cenas observa-se que zoomorfos e antropomorfos não conservam a mesma nitidez e ao menos macroscopicamente isso não decorre de rupturas na conservação do painel.

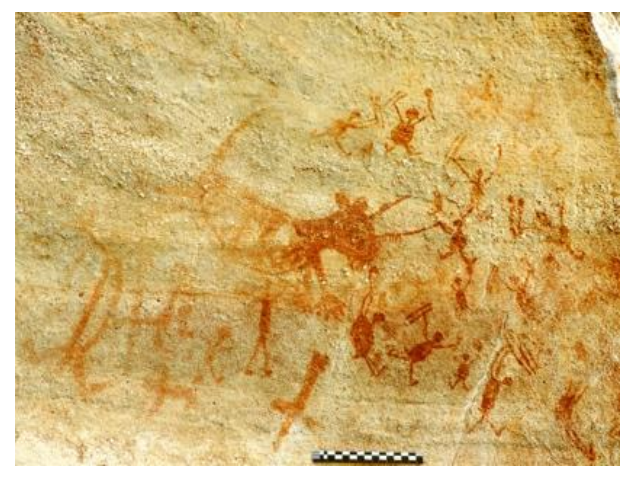

Figura 11: Diferente nitidez para os grafismos de antropomorfos $\mathrm{s}$ e zoomorfos. Sítio Toca da Serrinha I.

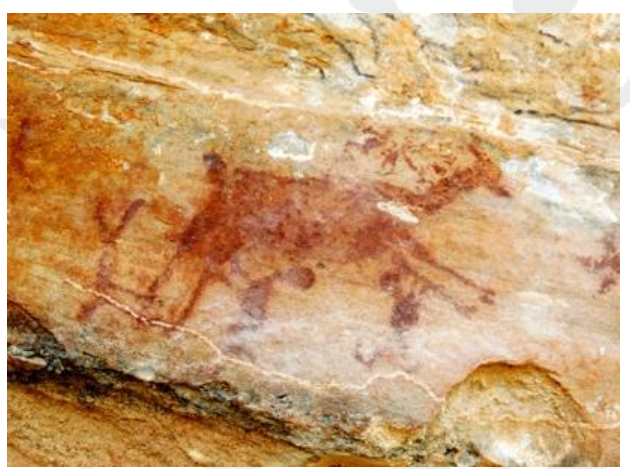

Figura 12: Diferente nitidez para os grafismos de antropomorfos e zoomorfos. Sítio Toca do Estevo III. 
A variável do tipo de traço foi aqui utilizada para avaliar a concepção do lineamento formador dos grafismos, se formado por traços contínuos, finos e precisos; ou se formado por traços descontínuos, grossos e sem muita precisão (Quadro 4).

\begin{tabular}{|l|l|}
\hline Traço & Diferentes \\
\hline Semelhantes & Sítio Toca das Cabaceiras \\
\hline
\end{tabular}

Quadro 4. Demonstrativos de cenas com elementos que apresentam elaboração gráfica semelhantes e diferentes.

Quanto a análise de semelhanças e diferenças gráficas entre componentes zoomorfos e antropomorfos da mesma cena de caça, pode-se verificar a existência de dois grupos de cenas, um que constitui-se por 30 cenas com grafismos que guardam semelhanças entre seus componentes e outro constituído por 12 cenas cujos grafismos possuem componentes de apresentação gráfica distintos.

Utilizando os mesmos critérios avaliativos no que se refere ao tipo de caça pode-se observar que a dominância das cenas que apresentam diferenças gráficas estão relacionadas a cena de caça de onça (7), seguidas de tatu (2) e veado (3). 


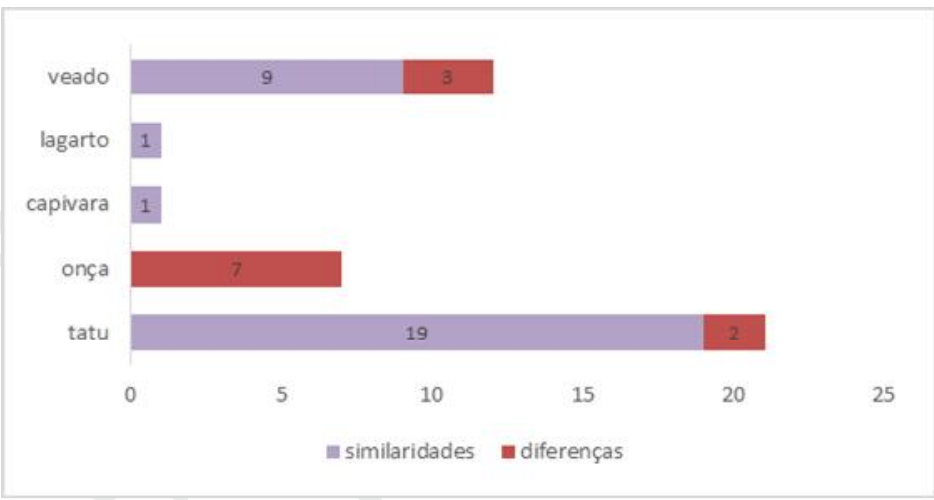

Gráfico 4: Similaridades e diferenças na elaboraçao do traço entre os componentes das cenas de caça.

A análise dessa variável permitiu observar que todas as cenas de caça de onça tem características distintas para traços. A cena do sítio Toca do Una I, é o que revela uma considerada desarmonia gráfica, por apresentar uma figura de contorno aberto ${ }^{10}$ (zoomorfo) e uma figura do complexo estilístico Serra Talhada. Uma das características do tipo de figura de contorno aberto é o de não apresentar cenas, todos os elementos desses grafismos evidenciados até o momento na Área Arqueológica Serra da Capivara estão isolados ou em composição hermética com outros do mesmo tipo gráfico (Figura 13). Para essa cena destaca-se também, como mencionado anteriormente, o apresamento manual e a caça por apenas dois indivíduo.

Outras imagens que se destacam na análise são as duas cenas de caça do sítio Toca das Cabaceiras, onde as figuras zoomorfas estão representadas com vários antropomorfos, essas figuras apresentam-se com traços grossos e não lineares, enquanto os antropomorfos com traços finos e precisos (Figura 14)

\footnotetext{
${ }^{10}$ Termo sugerido, por Guidon, (1984), e trabalhado por Cisneiros (2008) para Serra da Capivara, contorno aberto, diz respeito principalmente a técnica de execução, os contornos e linhas que delimitam a figura não se fecham. Os contornos são os delineadores da figura, asseguram sua forma e movimento.
} 


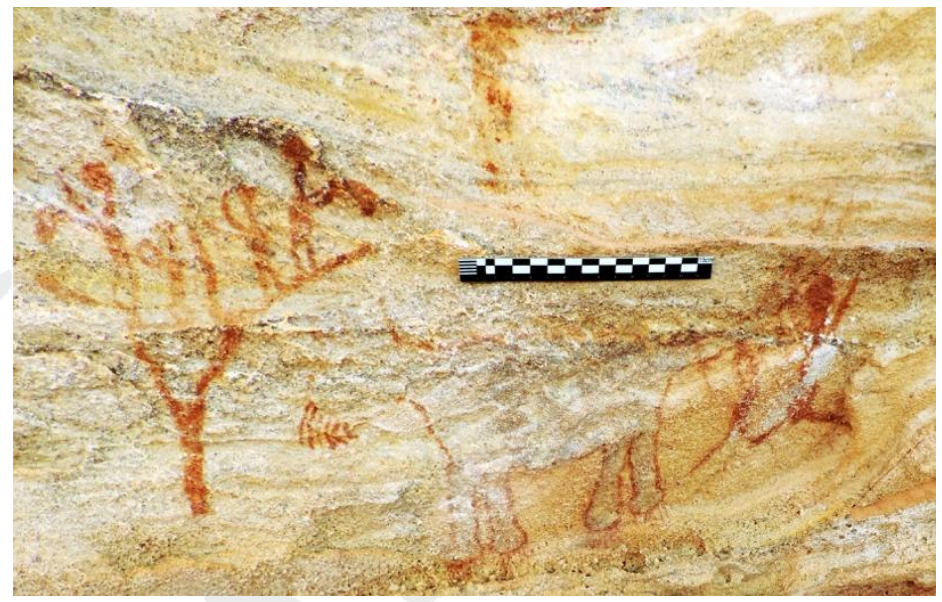

Figura 13: Figuras antropomorfas e zoomorfa com elementos gráficos diferentes. Sítio Toca do Uma I.
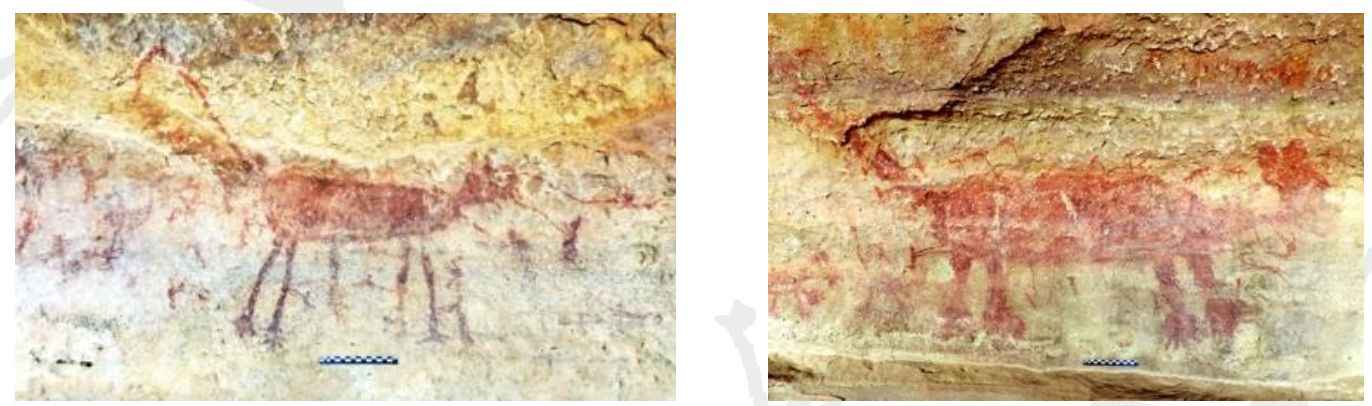

Figura 14: Figuras antropomorfas e zoomorfas com elementos gráficos diferentes nas cenas 1 e 2 do sítio Toca das Cabaceiras.

Para as duas cenas de tatus, pode-se observar na cena do sítio Toca do Baixão da Vaca, diferenças gráficas entre zoomorfos e antropomorfos, o zoomorfo apresenta traços precisos e finos com atenção aos detalhes anatômicos, enquanto os antropomorfos, tem traços grossos e sem muita precisão, outro aspecto já mencionado anteriormente refere-se a singularidade dessa cena se apresentar como caça coletiva de tatu e com presença de armas (Figura 15), ação não muito comum para a caça desse animal. No sítio Toca da Extrema II, observa-se a cena caça em que o zoomorfo tem traços muito mais finos e 
precisos que o antropomorfo, apresenta também uma sobreposição do antropomorfo sobre o zoomorfo, de aspecto incomum para esse tipo de grafismos (Figura 16).

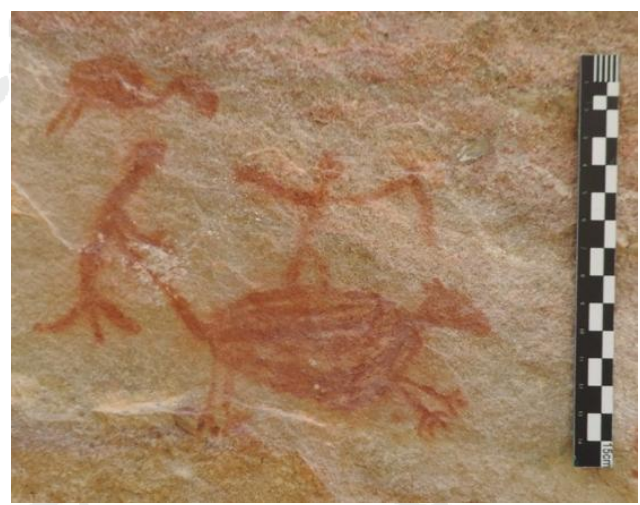

Figura 15: Antropomorfos e zoomorfos com elementos gráficos diferentes. Sítio Toca do Baixão da Vaca.

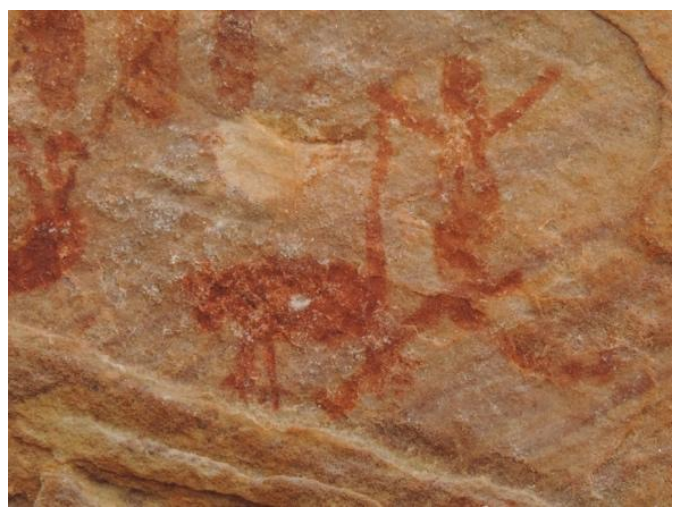

Figura 16: Antropomorfos e zoomorfos com elementos gráficos diferentes. Sítio Toca da Extrema II.

Para os veados observou-se distinção gráfica para três cenas. Na cena 3 do sítio Toca do Estevo III, observa-se um zoomorfo (veado) de grande dimensão sendo capturado de forma manual por três antropomorfos, o que também configura-se em um tipo de caça singular para essa espécie de animal, os dois dos antropomorfos possuem traços e matiz diferentes do zoomorfos e também distintos do antropomorfo maior que tem traços não muito precisos e grossos, sua posição de apresentação, também é contranatura em relação a apresentação do zoomorfo (Figura 17). Na cena do sítio Toca do Veredão II, antropomorfo e zoomorfo são realizados com cores diferentes, embora o traço de ambos se assemelhe em precisão, continuidade e espessura, a cor e a proporção que guardam entre si sugere diferença na execução (Figura 18). Para a cena do sítio Toca do Sobradinho II zoomorfos e antropomorfos possuem técnicas de execução gráfica 
diferenciadas o antropomorfo é bastante simples, sem preenchimento interno, enquanto o zoomorfo tem muitos detalhes anatômicos e de preenchimento (Figura 19).

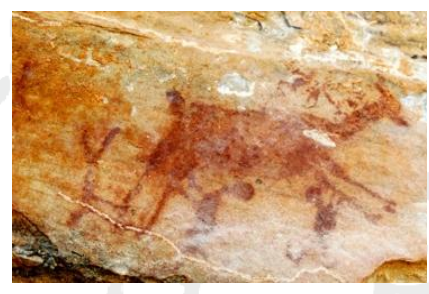

Figura 17: Antropomorfos e zoomorfos com elementos gráficos diferentes. Cena 3 do Sítio Toca do Estevo III.

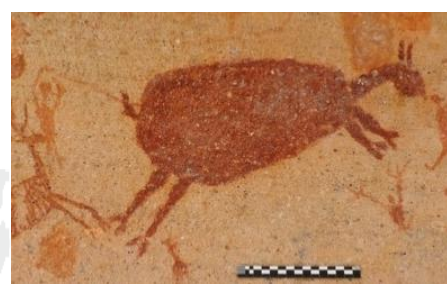

Figura 18: Antropomorfos e zoomorfos com elementos gráficos diferentes. Sítio Toca do Veredão II.

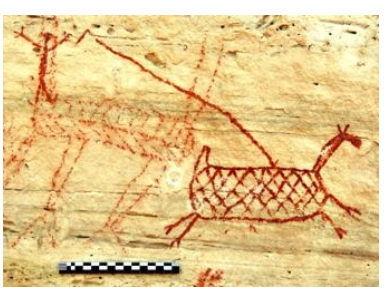

Figura 19: Antropomorfos e zoomorfos com elementos gráficos diferentes. Sítio Toca do Sobradinho II.

\section{CONSIDERAÇÕES FINAIS}

Devido a persistência dos registros rupestres no tempo, estes apresentam um caráter dinâmico tanto para o significante, quanto para o significado. As pinturas e gravuras estão sujeitas a um fluxo contínuo de alterações. Essas alterações podem se dar de maneira natural por intempéries, ou também adição de novos grafismos à painéis já existentes. Os diferentes conhecimentos de preparo de tintas utilizadas em pinturas podem apresentar durabilidade distinta, apagando-se ou persistindo no tempo de modo irregular, contribuindo para o dinamismo. No caso de novos grafismos, esses podem adensar o painel, tornando-o um palimpsesto com muitas sobreposições, ou podem também dar significações diferentes a grafismos já existentes, a exemplo: uma onça desenhada anteriormente, tinha um significado para o grupo autor, antropomorfos pintados posteriormente em torno da mesma onça, resignificam a imagem para o novo grupo. 
Essa dinâmica da produção gráfica, persistente durante milênios, possibilita à pesquisa arqueológica a identificação similaridades e diferenças gráficas. A análise dessas semelhanças e diferenças pode ser um indicativo de momentos gráficos distintos e de ressignificações de imagens ao longo do tempo.

Ao observar um painel rupestre, este apresenta-se ao observador como uma unidade, apresentar-se de modo sincrônico, no entanto faz-se necessário uma análise mais acurada para perceber que muitos daqueles elementos contidos em um painel rupestre podem ter sido adensados ao longo do tempo, depois dos primeiros grafismos.

Dado os limites de técnicas hodiernas para sujeitar as pinturas a uma datação precisa, a observação de similaridades e diferenças gráficas se faz necessária, para a distinção momentos e unidades gráficas dentro de um mesmo painel.

As constantes reutilizações dos abrigos por diferentes grupos demonstram a importância de certos ambientes para esses autores ao longo de diversas gerações. As múltiplas sobreposições de grafismos sobre representações prévias sem respeitar o já desenhado ou a transformação temática das cenas a partir da incorporação de novas figuras denotam uma interferência ou até mesmo uma ruptura, sobre intencionalidades de uma tradição ou grupo autor anterior.

Apesar da impossibilidade de estabelecer os intervalos de tempo que decorre entre as possíveis intervenções ou horizontes de representações, essa análise permitiu observar distinções gráficas dentro de uma mesma cena. A comparação dos resultados obtidos em 
vários conjuntos permitiu igualmente, sugerir uma possível diacronia entre os elementos de um arranjo gráfico, visto hoje como uma cena de caça.

Quanto às variáveis trabalhadas na identificação de semelhanças e diferenças gráficas nas cenas de caça do Parque Nacional Serra da Capivara, observou-se que a cor e nitidez, trabalhadas de forma macroscópicas coincidiram com a análise do traço, embora esta última se revelou mais determinante para a distinção de elementos gráficos.

Em relação ao tipo de caça e aos animais caçados, percebeu-se que as cenas de caça ao tatu em sua maioria não apresentaram diferenças gráficas entre zoomorfos e antropomorfos. Notou-se que nessas cenas o animal é caçado manualmente agarrado pela cauda, sem uso de armas, apenas em uma das cenas de caça ao tatu, apresenta-se fora desse padrão, por ser coletiva e apresentar presença de armas, porém, essa mesma cena está composta por antropomorfos e zoomorfo com execução gráfica distinta. A outra cena de distinção gráfica é a única em que o antropomorfo se sobrepõe em tamanho ao zoomorfo, para todas as outras cenas existe um equilíbrio de tamanho, que embora não seja proporcional a realidade, se se mantém constante para todas as demais cenas.

As cenas de caça de veados, em sua maioria, não apresentou diferenças gráficas entre zoomorfos e antropomorfos, e preponderantemente são caças coletivas e com uso de armas. Apenas em três cenas observa-se diferenças em relação ao aspecto gráfico. A análise também demonstrou similaridade gráfica para a cena de caça restante à capivara (1) ao lagarto (1) .

A análise de similaridade e diferenças gráficas para a caça a onça, em sua maioria apresentou diferenças gráficas entre zoomorfos e antropomorfos. Notou-se que nessas 
cenas o animal é caçado por antropomorfos cuja execução gráfica é diferente no que se refere a espessura do traço e precisão técnica, assim, como no tamanho dos grafismos, as onças são sempre apresentadas em tamanho muito maior do que os antropomorfos, embora guardem proporções padronizadas entre si.

Os dados obtidos com essa pesquisa permitem trabalhar com a hipótese de que esses grafismos podem ter sido executados no painel de forma diacrônica. A evolução dos motivos, temas, padrões de continuidade e mudança de elementos gráficos parecem traduzir-se em diferentes grupos e momentos gráficos, cujas diferenças foram marcadas pela utilização de tipos de traços distintos na composição da cena. De certo não exclui também a possibilidade de se tratar de técnicas diferentes que cumprem funções diferentes dentro de um mesmo grupo. Assim, essa pesquisa corrobora com a ideia de que uma composição lida em um painel rupestre como uma cena nem sempre possui uma unidade gráfica.

\section{REFERÊNCIAS BIBLIOGRÁFICAS}

ARNHEIM, R. Arte e percepção visual: uma psicologia da visão criadora. São Paulo: Ed. Thomson Learning. 2006.

CISNEIROS, D. Similaridades e Diferenças nas Pinturas Rupestres Pré-históricas de Contorno Aberto no Parque Nacional Serra da Capivara - PI. Tese (Doutorado em Arqueologia). Universidade Federal de Pernambuco. Recife. 2008.

FELICE, G. D.; GUIDON, N.; MENDES, V. R. A evolução da paisagem no Pleistoceno superior/Holoceno, na região do Parque Nacional Serra da Capivara. In Os Biomas e as Sociedades Humanas na Pré-História da Região do Parque Nacional Serra da Capivara, Brasil; Pessis, A.-M., Martin, G., Guidon, N., Eds.; A\&A: São Paulo, Brasil. 2014.

GUÉRIN, C. FAURE, M.; CURVEllo M. A.; HUGUENEY, M., MOURERCHAUVIRE C. A Fauna Pleistocênica do Piauí (Nordeste do Brasil): Relações 
Paleoecológicas e Biocronológicas. FUMDHAMentos - Revista do Museu do Homem Americano, São Raimundo Nonato, v.1. n.1, p. 259-336. 1996.

GUÉRIN, C.; FAURE, M. La biodiversité mammalienne au Pléistocène supérieurHolocène ancien dans la Région du Parc national Serra da Capivara (SE du Piauí, Brésil). In II Sympósio Internacional "O Povoamento das Américas”, São Raimundo Nonato, PI, Brasil; FUMDHAMentos: São Raimundo Nonato, Brasil, Volume 7, pp. 80-93. 2008.

GUÉRIN, C.; FAURE, M. Paleontologia da Região do Parque Nacional Serra da Capivara. In: Os Biomas e as z na Pré-História da Região do Parque Nacional Serra da Capivara, Brasil; Pessis, A.-M., Martin, G., Guidon, N., Eds.; A\&A: São Paulo, Brasil. 2014.

GUIDON, N. Les Peintures Rupestres de Várzea Grande, Piauí, Brésil. Cahiers d’Archéologie d’Ameririque du Sul. Paris, Écoloe de Hautes Étude em Sciences Sociales, n. 3.1975.

GUIDON, N. Tradições e estilos da Arte Rupestre no Sudeste do Piauí. Pré-história Brasileira Aspectos da Arte Parietal. Catálogo de Exposição. São Paulo, USP, p.19-20. 1981.

GUIDON, N. Tradições Rupestres da Área Arqueológica de São Raimundo Nonato, Piauí, Brasil. Revista Clio - Série Arqueológica, Recife, n. 5, p. 5-10. 1989.

MARTIN, G. Pré-História do Nordeste do Brasil. Recife: Ed. Universitária da UFPE. 1999.

PANOFSKY. E. Significado nas Artes Visuais. Trad. M. C. F. Keese e J. Guinsburg 3 a. ed. São Paulo: Perspectiva, 2007.

PESSIS, A-M. Apresentação gráfica e representação social na tradição Nordeste de pintura rupestre no Brasil. Revista Clio - Série Arqueológica. Recife: UFPE, n. 5, p. 1118. 1989.

PESSIS, A-M. Art rupestre préhistorique: Premiers registres de la mise en scene. Tese (doutorado de Estado) - Université de Paris X - Nanterre. 1987.

PESSIS, A-M. Identidade e Classificação dos Registros Gráficos Pré-históricos do Nordeste do Brasil. Revista Clio - Série Arqueológica, Recife, n. 8, p. 35-68. 1992. 
PESSIS, A-M. Registros rupestres, perfil gráfico e grupo social. Revista Clio - Série Arqueológica, Recife, n. 9, p. 7-14, 1993.

SANCHIDRIAN, J. L. Manual de Arte Prehistórico. Barcelona: Ariel Prehistoria. 2001. 